\title{
Nanoparticle Assisted Coagulation of Aqueous Alumina Suspensions
}

\author{
Abdullah Fatih Çetinel ${ }^{*}$, Reinhard Anton Simon ${ }^{\mathrm{b}}$ \\ aKarlsruhe Institute of Technology, Institute for Applied Materials (IAM-WPT), \\ Hermann-von-Helmholtz-Platz 1, 76344 Eggenstein-Leopoldshafen, Germany \\ ${ }^{\mathrm{b}}$ ABB Switzerland Ltd, Corporate Research, Segelhofstrasse 1, 5405 Baden-Dättwil, Switzerland
}

Received: June 17, 2011

\begin{abstract}
Colloidal processing of ceramics offers a high potential to achieve homogeneous microstructures with improved material properties. In this study, a novel forming method is investigated, which was already applied successfully for the fabrication of ceramic matrix composites (CMC), but is also considered to be a suitable direct casting technique for the fabrication of advanced ceramics with tailored microstructure and properties. The so-called nanoparticle assisted coagulation method (NPAC) represents a modification of the hydrolysis-assisted solidification (HAS) technique. It promises green components with high green strength, uniform density as well as homogeneous and tailored microstructure. Electrostatically stabilized colloidal suspensions with high solid loadings were produced by dispersing various fractions of submicron alumina powder and aluminium hydroxide nano-powder in water without use of any organic binder. Rheology and coagulation kinetics of suspensions and green part properties were studied regarding to modifications of $\mathrm{pH}$ value, setting temperature, amount of setting agent, amount of nano-powder, solids loading and process parameters like ultrasound treatment. It could be revealed that the homogeneous core-shell arrangement of submicron and nanoparticles in the colloidal state can be transmitted to the green state, which improves the microstructure and green density of the green parts. For this, the NPAC method is seen as a promising technique for the fabrication of advanced ceramics with tailored microstructure and properties.
\end{abstract}

Keywords: direct casting, ceramic forming, rheology, green strength, cryo TEM, nano-particles, zeta potential, coagulation kinetics

\section{Introduction}

Advanced ceramics are manufactured typically by using conventional powder technologies. For enhanced mechanical and functional properties usually very fine powders in the scale of submicron or nanometer are desired. Ultrafine powders, however, exhibit significant agglomeration in initial state. In general, agglomerates yield to considerable material flaws and inhomogeneity during the fabrication process and represent a common reason for the failure of ceramic components ${ }^{1}$. During forming the powder is processed to a green body exhibiting a particular density and microstructure. It is necessary to control the density and microstructure of the green part carefully to obtain a ceramic part with favourable mechanical properties. By reducing the size and number of defects and flaws, which depend in a large scale on the applied processing method, the average strength and reliability of ceramic components can be improved significantly. Therefore, special effort is inevitable for the control of defects and microstructure of green parts ${ }^{2}$.

Recently, more attention is paid to the so-called colloidal processing techniques for ceramics. As a wet shaping method that enables near net shaping of complex shaped ceramics, direct casting (DC) methods exploit colloidal processing techniques for enhanced material properties.

*e-mail: fatih.cetinel@kit.edu
DC methods yield to well-dispersed ceramic particle networks by controlling interparticle forces, resulting in homogeneous and dense suspensions combined with low viscosity for good flowability and mouldability. In general, stabilization of colloidal suspensions is achieved by electrostatic, steric, electrosteric or depletion forces among the ceramic particles. A controlled destabilization of stabilized and highly loaded suspensions is necessary to enable consolidation to a homogeneous, dense and stiff green part with controlled shrinkage and favourable strength. The theoretical background of colloidal processing and stabilization mechanisms as well as a detailed review of DC methods with description of other novel approaches to form green bodies directly from a dense suspension are given by Lewis et al. ${ }^{3}$ and Sigmund et al. ${ }^{4}$.

Aqueous injection moulding, also known as the River process $^{5}$, uses non-adsorbed polymers for stabilization. Freeze casting is based on the liquid-solid transition of water-based liquids as dispersing medium to freeze the homogeneous and well-dispersed state of the slurry ${ }^{6}$. Gel casting exploits the polymerization of monomers for the consolidation of a colloidal suspension ${ }^{7}$. Temperature induced forming enables gelation of aqueous suspensions at elevated temperature ${ }^{8}$. Direct coagulation casting (DCC) is based on the time-delayed destabilization of a suspension 
or sol by manipulation and control of the interparticle forces, e.g. via shifting the $\mathrm{pH}$ value of a suspension or sol to the isoelectric point (IEP) ${ }^{9-11}$. The consolidation mechanisms of the hydrolysis assisted solidification (HAS) are based on the chemical bonding of water by hydrolysis of aluminium nitride (AIN), formation of ammonia and a subsequent precipitation of amorphous and crystalline aluminium hydroxide h2-14. $^{12}$.

The nanoparticle assisted coagulation (NPAC) method proposed by Simon ${ }^{15,16}$ has some similarities to DCC and HAS, but represents an exceptional approach, as a novel microstructural design is applied for the stabilization of a colloidal suspension. In a favourable approach, electrostatically stabilized colloidal suspensions with core-shell arrangement of submicron and nanometer-scaled ceramic particles are fabricated by controlling interparticle forces carefully without use of any organic binder. Initially, the novel NPAC technique was investigated to meet the requirements for a promising approach in the development of all-oxide continuous fiber-reinforced ceramic matrix composites. However, it turned out that the process is also a suitable direct casting technique for the fabrication of advanced monolithic ceramics with tailored microstructure and properties ${ }^{17,18}$.

In this study, the rheology, coagulation kinetics and colloidal stability as well as green part properties of electrostatically stabilized alumina-aluminium hydroxide suspensions were investigated with respect to modifications in (i) $\mathrm{pH}$ value, (ii) setting temperature $\mathrm{T}_{\text {set }}$, (iii) amount of setting agent $\mathrm{m}_{\mathrm{AIN}}$, (iv) amount of nano-powder $\varphi_{\text {nano }}$, (v) solids loading $\Phi$ and (vi) the process parameter ultrasound treatment. Characteristic strength, drying shrinkage and relative density of green parts were determined as a function of solids loading and nano-powder fraction. Scanning and transmission electron microscopy were used to investigate the microstructure of suspensions and green parts in order to find out relationships between process parameters and properties of green parts. The main goal of this work is to contribute to a better understanding in the fundamental mechanisms of NPAC. Alumina-aluminium hydroxide suspensions were taken as a model system to enable correlations among composition, microstructure and macroscopic material properties.

\section{Experimental}

Suspensions were prepared containing commercial submicron alumina (APA-0.5, Sasol North America, USA), aluminium hydroxide (AlOOH, boehmite) as nano-powder (Disperal, Sasol North America, USA) and aluminium nitride (AlN Grade C, H.C. Starck, Germany) as setting agent. Specifications and nomenclature of the used powders and prepared mixtures are listed in Table 1. Before dispersing, the powder fractions were mixed by using a laboratory scale shaker (Turbula T2C, Willy A. Bachofen, Switzerland). A closed loop process was realized by using a dissolver (Dispermat AE, VMA-Getzmann, Germany), a laboratory stirred high-energy media mill (MiniCer, Netzsch, Germany) with yttrium stabilized zirconia grinding balls (Silibeads ZY, Sigmund Lindner, Germany) with a median diameter of 0.6 to $0.8 \mathrm{~mm}$ and an ultrasonic homogenizer (Branson 450, Branson Ultrasonics, USA) for enhanced homogenization quality. The powder mixture was added to deionized water (Direct-Q3 Ultrapure Water Systems, Millipore, USA) in several portions. Nitric acid was added to the suspension to countervail the $\mathrm{pH}$ shift to alkaline. A $\mathrm{pH}$ value of $4.0 \pm 0.1$ was kept continuously to maintain a minimum of suspension viscosity during processing. The suspension was continuously cooled to $25-30{ }^{\circ} \mathrm{C}$ at each processing step. Before casting, aluminium nitride was added to the suspensions and homogenized by vigorous stirring and by using a laboratory ultrasonic homogenizer (Bandelin Sonopuls HD2200, Progen Scientific, UK). Few drops of 2-Octanol were added as defoamer before vacuum degassing by simultaneous stirring. The suspensions were

Table 1. Specifications of applied raw materials and suspension compositions.

\begin{tabular}{|c|c|c|c|}
\hline & AIN grade $C$ & APA-0.5 & Disperal \\
\hline \multicolumn{4}{|l|}{ Raw materials } \\
\hline Median particle size $d_{50}$ & $1.12 \mu \mathrm{m}$ & $0.3 \mu \mathrm{m}$ & $0.03 \mu \mathrm{m}$ \\
\hline Specific surface area & $4 \mathrm{~m}^{2} \cdot \mathrm{g}^{-1}$ & $8 \mathrm{~m}^{2} \cdot \mathrm{g}^{-1}$ & $180 \mathrm{~m}^{2} \cdot \mathrm{g}^{-1}$ \\
\hline $\mathrm{pH}$ value at $\operatorname{IEP}(\xi=0 \mathrm{mV})$ & - & 9.1 & 9.3 \\
\hline Zeta potential $\xi$ at $\mathrm{pH}=4.0$ & - & $64.6 \mathrm{mV}$ & $41.3 \mathrm{mV}$ \\
\hline \multicolumn{4}{|l|}{ Compositions } \\
\hline $\mathrm{A} 00 \mathrm{~A}$ & $1.5^{*} / 3.0^{*} / 4.5^{*} \%$ & 0 wt. $(\%)$ & 100 wt. $(\%)$ \\
\hline $\mathrm{A} 20 \mathrm{~A}$ & $1.5^{*} / 3.0^{*} / 4.5^{*} \%$ & 20 wt. (\%) & 80 wt. $(\%)$ \\
\hline $\mathrm{A} 40 \mathrm{~A}$ & $1.5^{*} / 3.0^{*} / 4.5^{*} \%$ & 40 wt. (\%) & 60 wt. (\%) \\
\hline A60A & $1.5^{*} / 3.0^{*} / 4.5^{*} \%$ & 60 wt. $(\%)$ & 40 wt. (\%) \\
\hline A70A & $1.5^{*} / 3.0^{*} / 4.5^{*} \%$ & 70 wt. $(\%)$ & 30 wt. (\%) \\
\hline $\mathrm{A} 80 \mathrm{~A}$ & $1.5^{*} / 3.0^{*} / 4.5^{*} \%$ & 80 wt. $(\%)$ & 20 wt. (\%) \\
\hline A90A & $1.5^{*} / 3.0^{*} / 4.5^{*} \%$ & 90 wt. $(\%)$ & 10 wt. $(\%)$ \\
\hline A100A & $1.5^{*} / 3.0^{*} / 4.5^{*} \%$ & 100 wt. $(\%)$ & 0 wt. $(\%)$ \\
\hline
\end{tabular}

\footnotetext{
*According to the total amount of processed powder.
} 
filtered before casting by using a 125 micron sieve to remove potential contaminations. Cylindrical specimens with diameter of $20 \mathrm{~mm}$ and heights of $10 \mathrm{~mm}$ were casted using a non-porous metallic mold allowing an air bubble-free fabrication. In Figure 1 the processing steps are summarized in a flow chart. Brazilian disc tests were conducted to characterize the strength of consolidated dry samples according to Weibull statistics with at least 30 samples of each lot by using a universal tensile testing machine (Instron 1362, Instron Deutschland, Germany). To enable correlations among microstructure of the suspensions and green specimens, a cryo transmission electron microscope (Zeiss 922 Omega, Carl Zeiss, Germany) and a scanning electron microscope (1540EsB Cross Beam, Carl Zeiss, Germany) was used. A concentric cylinder viscosimeter (Phyisca UM/MC, Physica Messtechnik, Germany) was used to investigate the rheological behaviour of the colloidal suspensions by shear rate-controlled measurements in the range $0.1-1000 / \mathrm{s}$. Powder particle size, zeta potential and $\mathrm{pH}$ value of prepared suspensions were characterized by using an electroacoustic spectrometer (DT1200, Dispersion Technology, USA).

\section{Results and Discussion}

\subsection{Rheology}

In literature several mathematical models can be found describing the relationship between relative viscosity and solids loading expressed by the volume fraction ${ }^{19}$. The relative viscosity is defined as the quotient of the apparent viscosity of the suspension and the viscosity of the dispersant medium. In this study the Krieger-Dougherty model was exploited to describe the relationship among relative viscosity and solids loading of the suspensions:

$\eta_{r}=\left(1-\frac{\Phi}{\Phi_{c}}\right)^{-K \Phi_{c}}$

where $\eta_{\mathrm{r}}$ stands for the relative viscosity, $\Phi$ is the solids loading, $\Phi_{c}$ is the maximum (critical) solids loading and $\mathrm{K}$ stands for the particle shape factor, given as 2.5 for monodisperse hard-sphere systems ${ }^{3}$. Most ceramic suspensions, however, can be classified as soft-sphere systems considering the combination of attractive van der Waals forces and double-layer repulsion between colloidal particles, which is described by the well-known DLVO theory developed by Derjaguin and Landau ${ }^{20}$ and Verwey and Overbeek ${ }^{21}$. In this case, $\Phi_{c}$ in Equation 1 can be enhanced by considering the volume occupied by the soft layer around each particle and the irregular shape of the particles ${ }^{3}$.

Fitting the results of rheological measurements of various mixtures of submicron alumina and boehmite nano-powder by using Equation 1 results in compositiondependent $\Phi_{c}$ values and characteristic curves as illustrated in Figure 2. The maximum solids loading decreases with increasing nano-powder fraction. This is caused by a significant increase of the surface area of the powder in connection with the presence of an electrical double layer of the electrostatically stabilized suspensions that results in an

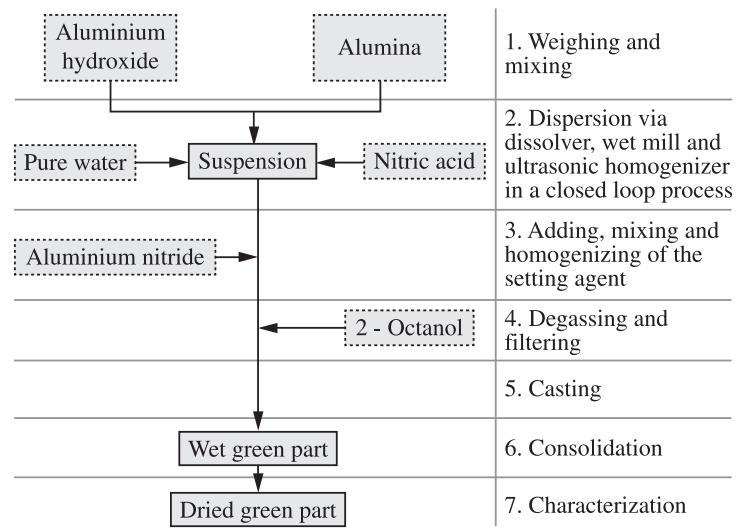

Figure 1. Flow diagram of NPAC processing steps.

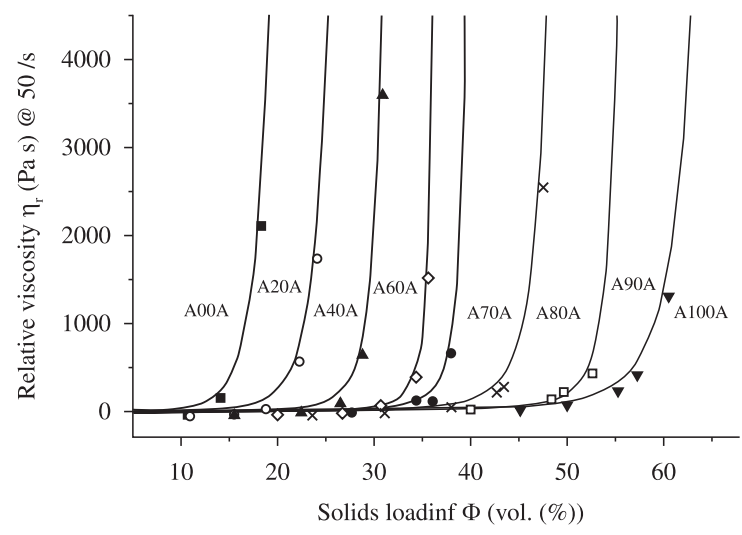

Figure 2. Fit of viscosity curves of alumina-aluminium hydroxide suspensions in dependency on solids loading according to the Krieger-Dougherty equation.

increase in the hydrodynamic particle radius and, thus, in a reduction in $\Phi_{c}$ with decreasing particle size $e^{22}$. Furthermore, a needle-like morphology with high aspect ratio of the nano-powder also lowers the packing density of the powder mixture. The calculated $\Phi_{c}$ values exploiting Equation 1 result in, however, significantly higher values than the experimental observations, also reported in literature ${ }^{19}$. Maximum solids loadings of 34 vol. (\%) for boehmitesuspensions (corresponding to nomenclature A00A, see Table 1) up to 71 vol. (\%) for alumina suspensions (A100A, see Table 1) were calculated with correlation coefficients of approximately 0.98 , whereas the experimental observations revealed that solids loadings higher than 20 vol. (\%) for A00A and 61 vol. (\%) for A100A suspensions could not be achieved. Inter alia, this difference is caused by the fact that Equation 1 for hard-spheres was used for fitting, allowing higher $\Phi_{c}$ values, as the extension of the electrical double layer $\delta$ is not considered.

Further rheological investigations revealed that all suspensions show typical shear thinning or pseudoplastical behaviour, respectively, with flow indices $n<1$ according to the power law after Ostwald and de Waele ${ }^{23}$ :

$$
\eta=k \dot{\gamma}^{(n-1)}
$$


where $\eta$ stands for the apparent viscosity, $\gamma$ for the shear rate and $\mathrm{n}$ for the flow index. With increasing nano-powder fraction the flow indices also increase and approximate to Newtonian behaviour. In Figure 3 double logarithmic plots of the apparent viscosity against the shear rate are illustrated. Compositions with none or small amounts of boehmite, e.g. A100A, A90A and A80A, exhibit a different behaviour at low and high shear rates than mixtures with high amounts of boehmite, as A60A, A40A and A20A. One reason for the observed differences at low shear rates is assumed to originate in time dependent effects like transient viscosity peaks in the low-shear rate range (Figure 3), which may occur when the measuring point duration is chosen too short $^{24}$. However, it seems that this behaviour is more pronounced for diluted systems and suspensions with high amount of nano-powder, respectively.

Aluminium hydroxide has a considerable effect on rheology and packing characteristics of alumina suspensions, as it acts as a binder phase due to its adhesive gel-like nature ${ }^{25}$. For instance, an increase of viscosity could be observed at high shear rates for suspensions containing boehmite (Figure 3). Rheopectic (anti-thixotropic) flow behaviour of suspensions even with small amounts of boehmite was present, as shown in Figure 4. The viscosities measured ramping up from 0.1 to $1000 / \mathrm{s}$ exhibited lower values than the viscosities measured ramp down from 1000 to $0.01 / \mathrm{s}$ (Figure 4). The nano-powder exhibits a layered, needle-like structure with high aspect ratio. It is also well known that aluminium hydroxide is hydrophilic due to its capability to build up hydrated layers ${ }^{26}$. Since aluminium hydroxide is extremely fine, it gets absorbed over the alumina particle surface. Non-absorbed boehmite seems to generate depletion forces among coarse alumina particles caused by structural potential energy. A spacefilling network or gel forms and affects rheology and packing characteristics dramatically.

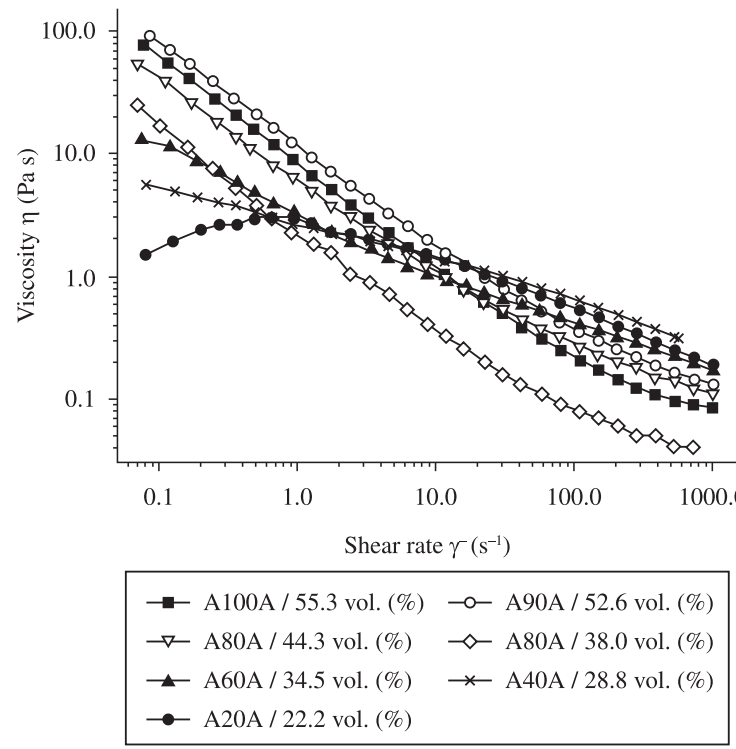

Figure 3. Flow behaviour of suspensions with varying nano-powder fraction.
Due to the fact that boehmite causes structural potential energy between alumina particles and exhibits a needle-like structure, higher shear stress and viscosity is caused when the suspension is sheared at very high rates compared to suspensions with none or small amounts of boehmite (Figure 3). It is assumed that non-adsorbed boehmite builds up a gel-like network of individual clusters connected with weak hydrogen bonds forming a volume-spanning network ${ }^{27}$. For suspensions with high amount of boehmite only a network of clusters is supposed to undergo shearing at low shearing rates and, hence, yielding to a lower resulting shear stress and viscosity compared to suspensions containing none or small amounts of boehmite. While shearing at high shear rates the cluster network of individual boehmite clusters connected with weak hydrogen bonds is broken down and each particle gets orientated, resulting in higher shear stress and viscosity values, respectively, compared to suspensions with none or small amounts of aluminium hydroxide. In Figure 5 a cryo-TEM image illustrates the arrangement of clusters of nano-particles around coarser alumina particles in a stabilized diluted suspension ( $\mathrm{pH}$ of 4 , solids loading of $0.5 \mathrm{wt}$. (\%)).

\subsection{Colloidal stability and coagulation kinetics}

The suspensions were consolidated exploiting the principles of the hydrolysis assisted solidification (HAS) according to Kosmac et al. ${ }^{12-14}$ by using aluminium nitride (AlN) as setting agent. Consolidation takes place by: (i) cumulative effect of internal water consumption due to hydrolysis of AIN (Equation 3); (ii) destabilization of the EDL due to zeta potential decrease caused by the $\mathrm{pH}$ shift from acidic to the IEP originiated from the formation of ammonia (Equation 4); (iii) the formation of amorphous $\mathrm{AlOOH}$ yielding an increase in viscosity; and (iv) chemical bonding of water (Equation 5).

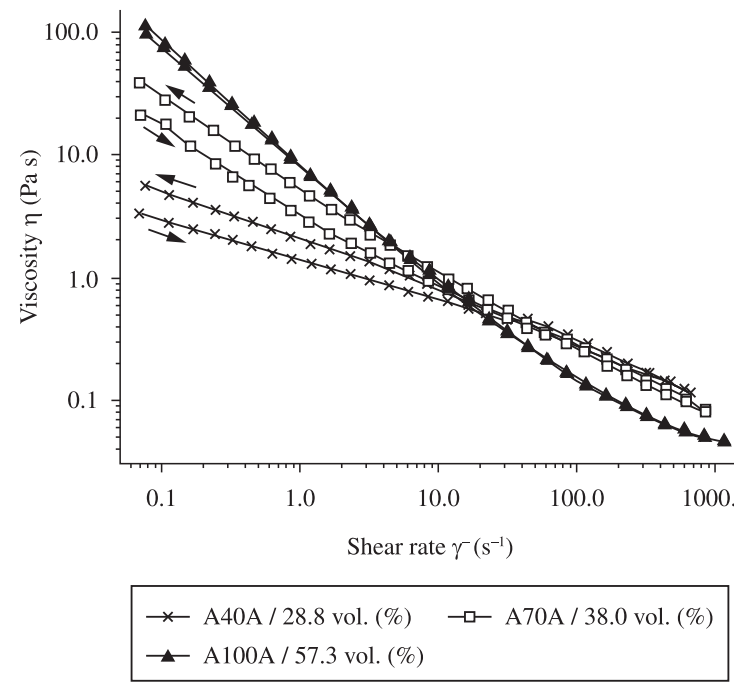

Figure 4. Viscosity-shear rate curves illustrating the rheopectic (anti-thixotropic) flow behaviour of suspensions containing aluminum hydroxide (arrows depict ramping up and down between 0.1 and $1000 / \mathrm{s})$. 
$\mathrm{AlN}+2 \mathrm{H}_{2} \mathrm{O} \rightarrow \mathrm{AlO}(\mathrm{OH})_{\text {amorphous }}+\mathrm{NH}_{3}$

$\mathrm{NH}_{3}+\mathrm{H}_{2} \mathrm{O} \longleftrightarrow \mathrm{NH}_{4}^{+}+\mathrm{OH}^{-}$

$\mathrm{AlO}(\mathrm{OH})+\mathrm{H}_{2} \mathrm{O} \longrightarrow \mathrm{Al}(\mathrm{OH})_{3}$

It was found that the solids loading $\Phi$ and amount of boehmite $\varphi_{\text {nano }}$ significantly affect the coagulation kinetics of the suspensions. In Table 2 coagulation setting times with different solids loadings for $1.5 \%$ AlN at $25{ }^{\circ} \mathrm{C}$ are summarized. In Figure 6 the dependency of $\mathrm{pH}$ value and zeta-potential of A100A suspensions with varying $\Phi$ are presented.

The influence of solids loading on coagulation kinetics is obvious (Figure 6). However, the final setting time, which was defined depending on the proper demoulding at approximately $\mathrm{pH}$ of 9.4, is not affected for suspensions containing none (A100A) and small amounts of boehmite (A90A), respectively (Table 2). For higher amounts of boehmite, as for A80A, the solids loading affects the

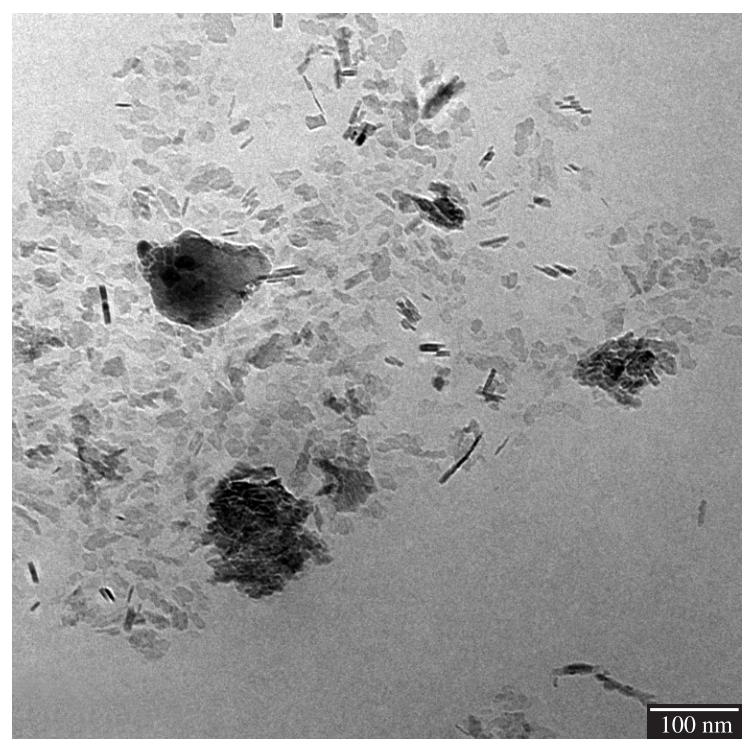

Figure 5. Cryo transmission electron micrograph of a diluted and electrostatically stabilized suspension (A80A) with $0.5 \mathrm{wt}$. (\%) at $\mathrm{pH}$ of 4.0 illustrating the arrangement of fine needle-like boehmite with high aspect ratio surrounding coarse alumina particles.

Table 2. Setting times for various compositions with different solids loadings at $25^{\circ} \mathrm{C}$ and $1.5 \%$ aluminium nitride.

\begin{tabular}{|c|c|c|c|c|c|}
\hline $\begin{array}{c}\text { Solids } \\
\text { loading } \Phi\end{array}$ & $\begin{array}{c}t_{\text {set }}^{*} \\
(\mathbf{A 1 0 0 A})\end{array}$ & $\begin{array}{c}\mathbf{t}_{\text {set }}^{*} \\
(\mathbf{A 9 0 A})\end{array}$ & $\begin{array}{c}t_{\text {set }}^{*} \\
(\mathbf{A 8 0 A})\end{array}$ & $\begin{array}{c}\mathbf{t}_{\text {set }}^{*} \\
(\mathbf{A 7 0 A})\end{array}$ & $\begin{array}{c}\mathbf{t}_{\text {set }}^{*} \\
(\mathbf{A 6 0 A})\end{array}$ \\
\hline 58.6 vol. (\%) & 8 hours & - & - & - & - \\
\hline 52.6 vol. (\%) & 8 hours & 12 hours & - & - & - \\
\hline 47.4 vol. $(\%)$ & 8 hours & 12 hours & 24 hours & - & - \\
\hline 44.2 vol. (\%) & - & 12 hours & 32 hours & - & - \\
\hline 40.3 vol. (\%) & - & - & - & 37 hours & - \\
\hline 38.1 vol. (\%) & - & - & 36 hours & - & - \\
\hline 36.0 vol. $(\%)$ & - & - & - & - & $>50$ hours \\
\hline
\end{tabular}

$\mathrm{pH}$ value for the end of consolidation was defined depending on proper mouldability of specimen $(\mathrm{pH} \sim 9.4)$. setting time apparently. Moreover, the influence of the nano-powder on the consolidation is much more obvious, as it yields to longer setting times. The remarkable effect of $\varphi_{\text {nano }}$ on the coagulation kinetics can be explained, when the surface chemistry of boehmite is considered. Aluminium hydroxide exhibits a comparably high specific surface with quantitatively more hydroxide groups $(-\mathrm{OH})$ on its surface than alumina. Consequently, the amount of hydroxide groups $(-\mathrm{OH})$ and the time necessary for a $\mathrm{pH}$ shift of $\mathrm{AlOOH}$ from acidic to alkaline is higher. Therefore, high amounts of boehmite act as buffer against the $\mathrm{pH}$ shift from acidic to alkaline (Equation 4) resulting in longer setting times, which was verified by titration experiments. The observation that the setting time is not influenced significantly by $\Phi$ is in agreement with another study, where this impact was found to become noticeable for a difference in solids loading above 10 vol. $(\%)^{13}$.

In Figure $7 \mathrm{pH}$ evolutions of A80A suspensions with $1.5 \% \mathrm{AlN}$ at $25^{\circ} \mathrm{C}$ and varying ultrasound treatment are given. For an unaged suspension processed by applying ultrasound continuously during the closed loop process a starting zeta potential of $56.5 \mathrm{mV}$ was measured (A80A-1), whereas the suspension aged for 1 hour exhibited a starting value of $48.8 \mathrm{mV}$ (A80A-2). In contrary, a zeta potential of $11.5 \mathrm{mV}$ was measured for an unaged suspension but without ultrasound treatment while processing (A80A-3). The zeta potential indicates the degree of stability of a suspension. Flocculation and, thus, destabilization of suspensions caused by attractive interparticle forces due to hydrogen bonds between boehmite particles are prevented through energy input via ultrasound and immediate processing without aging. As a result, destabilization of aluminium hydroxideloaded alumina suspensions occur when either no ultrasound treatment is performed or stabilized suspensions are aged. This observation supports the assumption that attractive forces are present among boehmite particles. Thus, it could be revealed that the destabilization of suspensions due to gelling of boehmite has a significant impact on the setting time. Besides, the influence of ultrasound treatment after adding of the setting agent to the suspension was investigated.

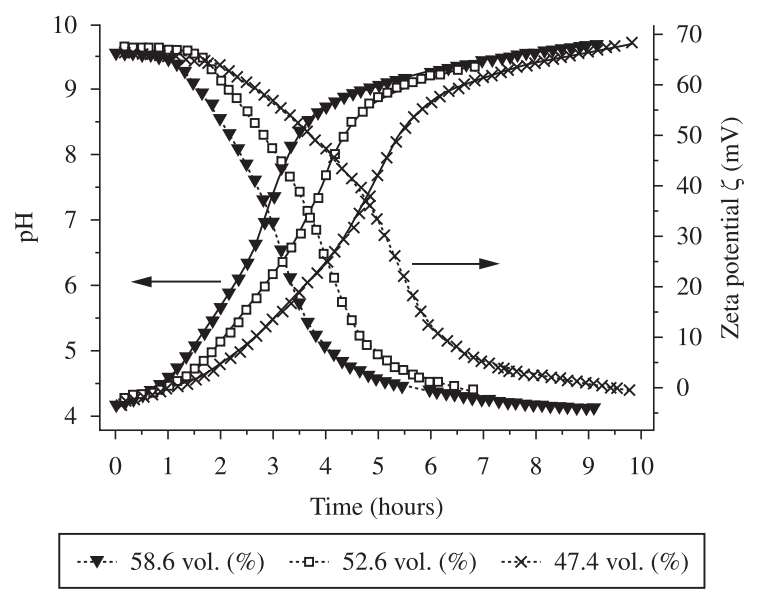

Figure 6. Zeta-potential and $\mathrm{pH}$ evolution versus setting time of stabilized A100A suspensions with different solid loadings $\Phi$ at $25^{\circ} \mathrm{C}$ and $1.5 \%$ AlN as setting agent. 


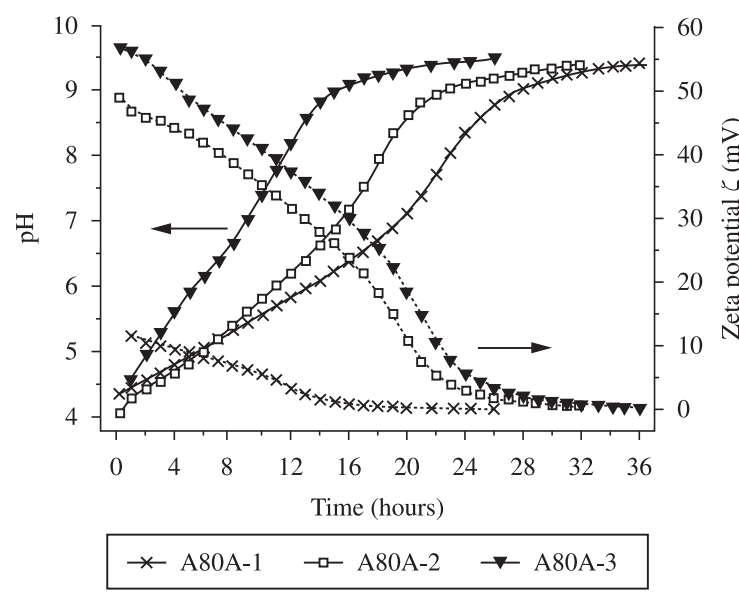

Figure 7. Zeta potential of an unaged (A80A-1) and 1 h-aged suspensions (A80A-2), which were treated with ultrasound continuously during fabrication, and an unaged suspension (A80A-3) without exposure to ultrasound during suspension processing.

A70A with $1.5 \%$ AlN at $25{ }^{\circ} \mathrm{C}$ treated with ultrasound after adding the setting agent showed a setting time of 37 hours (Table 2), whereas an untreated A70A suspension exhibited a setting time over 48 hours. This observation shows that an inhomogeneously distributed setting agent also affects the coagulation kinetics considerably.

The influence of the setting temperature $T_{\text {set }}$ was also found to be a further crucial parameter influencing the coagulation kinetics, which was also reported in literature ${ }^{12}$. In Figure 8 the effect of $\mathrm{T}_{\text {set }}$ on the setting time for $\mathrm{A} 90 \mathrm{~A}$ suspensions is illustrated. As expected, higher setting temperatures result in faster coagulation of the suspensions due to temperature-induced elevated reaction rates of the chemical reactions expressed in Equation 3-5. As a rough rule of thumb, reaction rates are increased by a factor 2 to 3 for a rise in temperature of $10^{\circ} \mathrm{C}^{28}$. This is in agreement with the observations made for A90A suspensions. Consolidation took place at $40{ }^{\circ} \mathrm{C}$ after 170 minutes, whereas coagulation was finished already after 80 minutes at $50{ }^{\circ} \mathrm{C}$.

The amount of setting agent $\mathrm{m}_{\text {AlN }}$ was also found to affect the coagulation kinetics remarkably. In Figure 9 the evolution of $\mathrm{pH}$ versus time during consolidation and the resulting setting time in dependency on $\mathrm{m}_{\mathrm{AlN}}$ for $\mathrm{A} 80 \mathrm{~A}$ suspensions are shown. An increasing amount of AlN results in shorter setting times and also increases the strength of the green parts, which will be discussed in the next chapter. Setting times are reduced, as ammonia formation and boehmite precipitation during hydrolysis of the setting agent are increased (Equation 3). For instance, the setting time decreases for A80A suspensions with 47.4 vol. (\%) and $1.5 \%$ AlN from 24 hours to 7 hours for 3.0\% AlN and 2.5 hours for $4.5 \%$ AlN (Figure 9). In contrary, for $1.5 \%$ AlN the setting time increases with decreasing solids loading (Table 2), whereas the setting time for $3.0 \%$ AlN stays constant at 7 hours for solids loadings between 38.1 and 47.4 vol. (\%). This leads to the conclusion that the influence of the solids loading on setting time can be diminished for suspensions with boehmite, when the amount of setting agent is chosen properly.

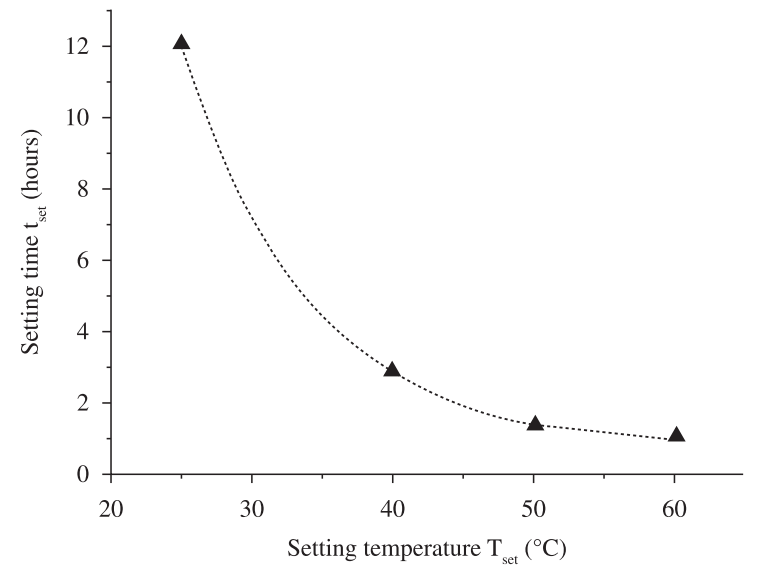

Figure 8. Effect of setting temperature $T_{\text {set }}$ on setting time $t_{\text {set }}$ for A90A suspensions.

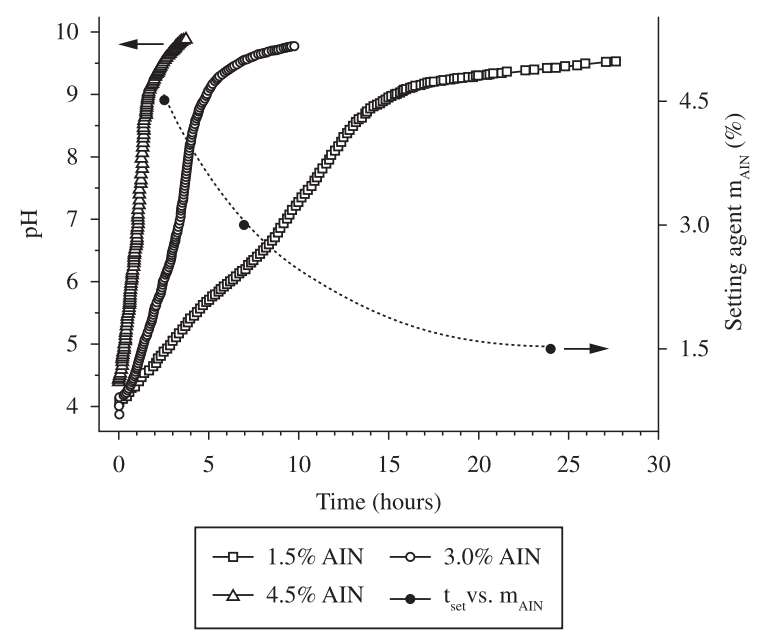

Figure 9. Influence of varying amounts of setting agent on the setting behaviour of A80A suspensions at $25^{\circ} \mathrm{C}$.

\subsection{Properties of green parts}

According to Figure 2 the critical solids loadings of alumina-boehmite suspensions are decreased with increasing amount of nanopowder $\varphi_{\text {nano }}$. Therefore, increasing drying shrinkage is expected with increasing $\varphi_{\text {nano }}$. For instance, volumetric shrinkage of $3.1 \pm 0.5 \%$ was calculated for A100A green parts with 58.6 vol. Comparable results were found in literature ${ }^{12,29}$. In Figure 10 the dependency of green density and drying shrinkage on solids loading and amount of nano-powder are presented. As high amounts of boehmite exhibit a limiting factor for high solids loadings, high shrinkage values result for suspensions with increasing $\varphi_{\text {nano }}$ due to a higher amount of water of the suspensions, e.g. $21.1 \pm 0.9 \%$ for A80A suspension with 47.4 vol. (\%). In comparison, A90A and A100A with identical solids loadings exhibit $10.4 \pm 0.9 \%$ and $7.7 \pm 0.7 \%$, respectively. Obviously, higher solids loadings result in lower volumetric drying shrinkage.

In contrary, for the green density it was found that with increasing $\varphi_{\text {nano }}$ the relative green density is also increasing (Figure 10). After drying, the aluminium hydroxide nano- 
powder phase and, additionally, the precipitated amorphous aluminium hydroxide phase (Equation 5) connects the host alumina particles and cause a considerable increase in green density and strength. A core-shell arrangement is built up consisting of fine boehmite particles surrounding coarser alumina particles. As a result, the nano-phase acts

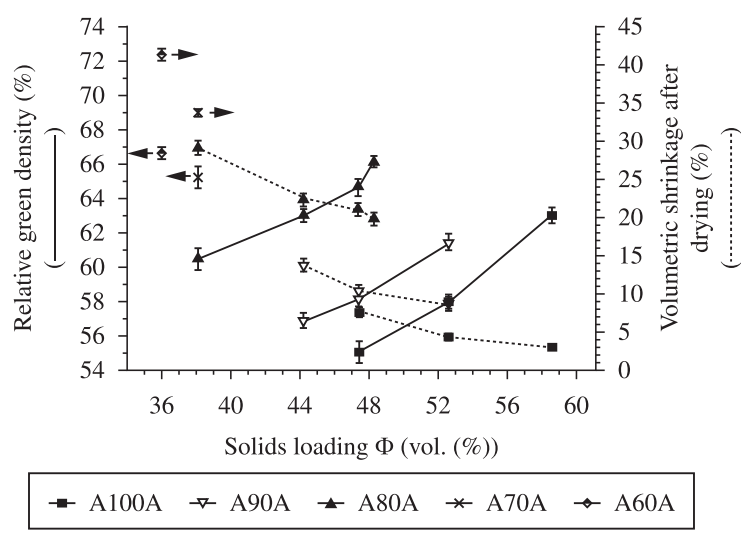

Figure 10. Green density and shrinkage of alumina-boehmite green parts in dependence of solids loading and amount of boehmite. as a kind of gap-filler within the alumina particle network. Therefore, higher $\varphi_{\text {nano }}$ yield to higher green densities, as gaps and necks between alumina particles are filled up. This observation could be verified by scanning electron microscopy of fracture surfaces of green parts with varying amount of $\mathrm{AlOOH}$ (Figure 11).

As a binder phase within the alumina network, boehmite also results in enhanced mechanical properties of green parts (Table 3), which was also reported in literature ${ }^{30}$. In Figure 12 strength and density values of green parts with 47.4 vol\% in dependency on the boehmite amount are shown. The characteristic strength correlates well with the relative density values of the green parts (Table 3 ). Weibull moduli were calculated and exhibited scattered values in the range of 3 to 12 , which might be enhanced, when finer sieves in the range of few microns would be used for filtering potential contaminations and residual agglomerations before degassing and casting ${ }^{29}$.

In literature a similar behaviour for the evolution of the density of extruded alumina-boehmite green parts was reported ${ }^{25}$. A maximum in relative green density of about $61 \%$ was found at $18.5 \mathrm{vol}$. (\%) boehmite corresponding to approximately $13.0 \mathrm{wt}$. (\%) boehmite in this study. Though, a maximum in green density could not be observed in our investigations. It is supposed that the applied

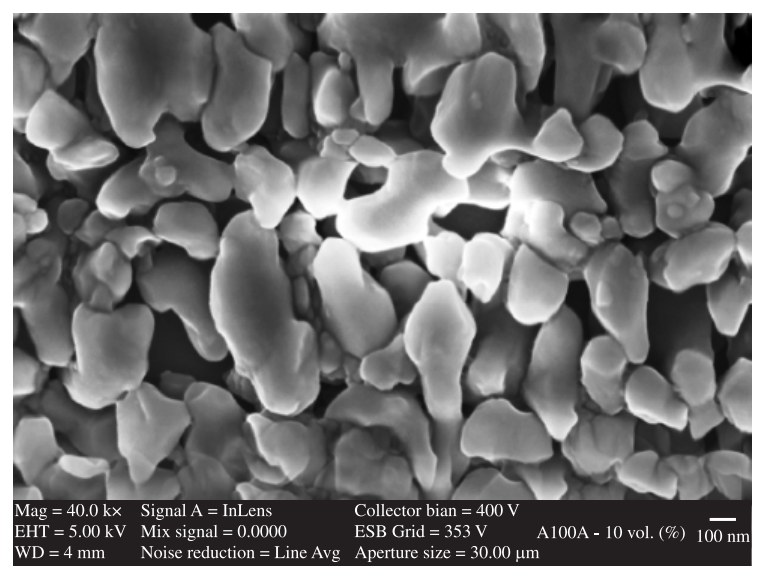

(a)

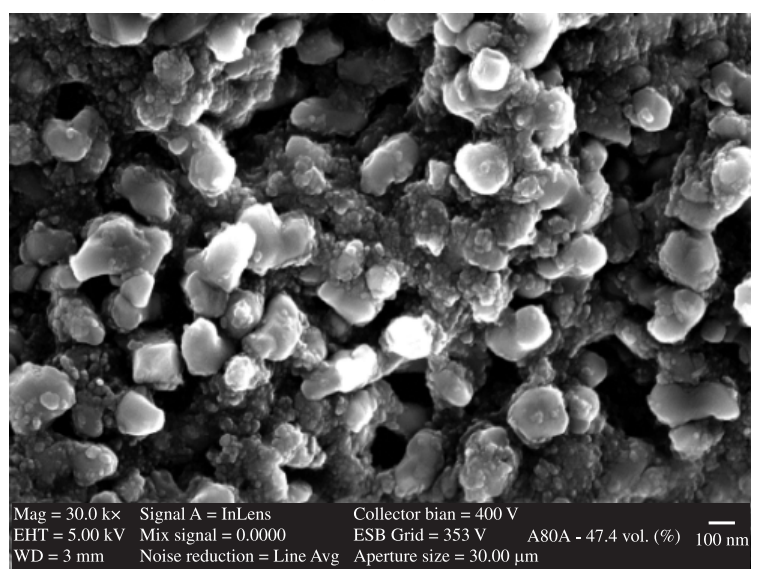

(c)

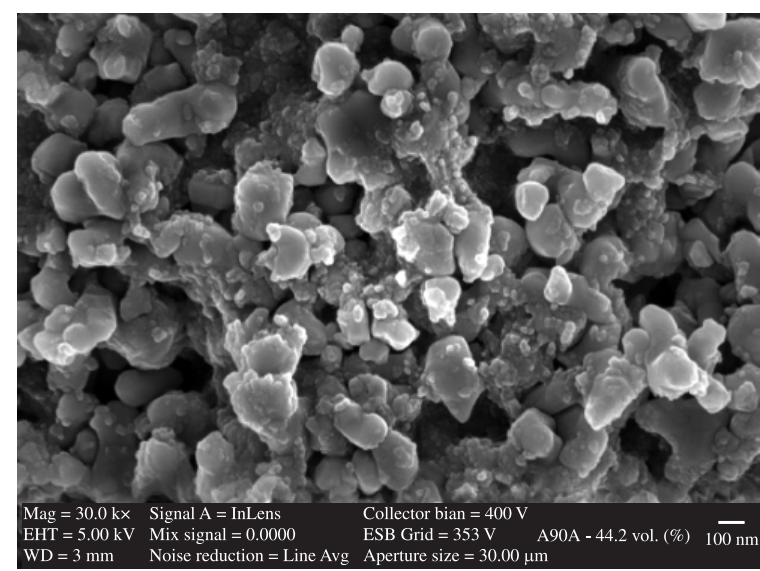

(b)

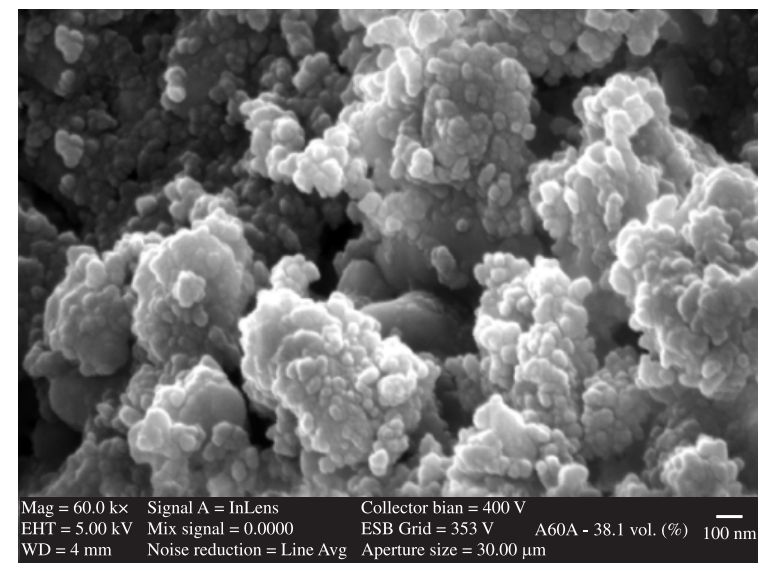

(d)

Figure 11. Microstructure of green parts with: a) none $\mathrm{AlOOH}(\mathrm{A} 100 \mathrm{~A})$ at 10 vol. (\%), b) 10 wt. (\%) $\mathrm{AlOOH}(\mathrm{A} 90 \mathrm{~A})$ at $44.2 \mathrm{vol} .(\%)$, c) 20 wt. (\%) $\mathrm{AlOOH}(\mathrm{A} 80 \mathrm{~A})$ at $47.4 \mathrm{vol} .(\%)$, and d) $40 \mathrm{wt}$ (\%) $\mathrm{AlOOH}(\mathrm{A} 60 \mathrm{~A})$ at $38.1 \mathrm{vol} .(\%)$. 
Table 3. Characteristic strength $\sigma_{0}$ of dry green parts measured (brazilian disc test).

\begin{tabular}{ccccc}
\hline $\begin{array}{c}\text { Solids } \\
\text { loading } \Phi\end{array}$ & $\begin{array}{c}\sigma_{\mathbf{0}} \\
(\mathbf{A 1 0 0 A})\end{array}$ & $\begin{array}{c}\sigma_{\mathbf{0}} \\
(\mathbf{A 9 0 A})\end{array}$ & $\begin{array}{c}\sigma_{\mathbf{0}} \\
(\mathbf{A 8 0 A})\end{array}$ & $\begin{array}{c}\sigma_{\mathbf{0}} \\
(\mathbf{A 7 0 A})\end{array}$ \\
\hline 57.3 vol. $(\%)$ & $0.64 \mathrm{MPa}$ & - & - & - \\
52.6 vol. $(\%)$ & $0.35 \mathrm{MPa}$ & $0.72 \mathrm{MPa}$ & - & - \\
48.3 vol. $(\%)$ & - & - & - & - \\
47.4 vol. $(\%)$ & $0.23 \mathrm{MPa}$ & $0.57 \mathrm{MPa}$ & $1.07 \mathrm{MPa}$ & - \\
44.2 vol. $(\%)$ & - & $0.52 \mathrm{MPa}$ & $0.62 \mathrm{MPa}$ & - \\
38.1 vol. $(\%)$ & - & - & - & $1.31 \mathrm{MPa}$ \\
\hline
\end{tabular}

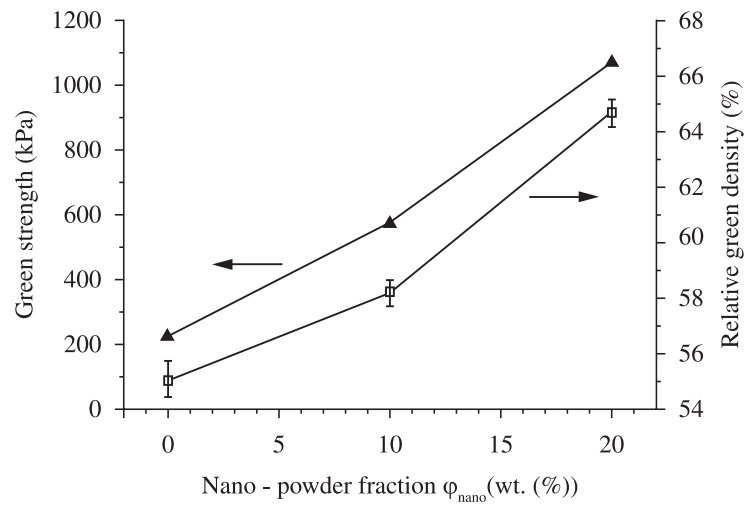

Figure 12. Characteristic strength (brazilian disc test) of Weibull analysis and density of green parts with 47.4 vol. (\%) solids loading.

processing method for the preparation of the suspensions has a considerable effect on compaction and mechanical properties. A different processing method was used by Ananthakumar and Warrie ${ }^{25}$ for the preparation of aluminaboehmite suspensions. In contrary, in this study suspensions were fabricated by controlling the electrochemistry of the suspension carefully that resulted in a core-shell arrangement of alumina and aluminium hydroxide, which could be transmitted to the green state successfully (Figure 11). The favourable gap-filling characteristic of the boehmite nanopowder yielding to an increase of green density and green strength seems to be limited to low $\mathrm{AlOOH}$ amounts only, when the suspension is not processed properly, which is not the case for the proposed NPAC method.

For this, NPAC is considered to be a favourable direct casting method for advanced ceramics with tailored microstructure, as the precipitation of boehmite on an alumina core phase during coagulation results in an additional $\mathrm{AlOOH}$ shell phase, which is transformed to alumina after sintering. However, NPAC should not be limited to alumina-based materials only, when appropriate combinations of coarse and fine powders as well as setting agents are considered.

\section{Conclusions}

Various processing parameters were investigated influencing the rheology and coagulation kinetics of alumina-aluminium hydroxide (boehmite) suspensions as well as the properties of green parts fabricated via nanoparticle assisted coagulation (NPAC). The colloidal suspensions exhibited shear thinning behaviour and showed pronounced rheopectic (anti-thixotropic) flow properties for increasing amount of boehmite due to an increase in gelling susceptibility. The effect of boehmite nano-powder on the packing characteristics was investigated, revealing a decrease of the maximum solids loading with increasing amount of boehmite. Destabilization of suspensions as a result of non-absorbed hydrophilic boehmite could be prevented by continuous ultrasound treatment during powder addition and after addition of the setting agent. It was found that boehmite causes a buffering effect regarding the $\mathrm{pH}$ shift of the suspension from acidic to the isoelectric point (IEP), which, in turn, causes longer setting times. Elevated setting temperatures resulted in faster coagulation due to temperature induced higher reaction rates of the chemical reactions during hydrolysis of the setting agent aluminium nitride (AlN). The amount of setting agent was also found to affect the coagulation kinetics remarkably. Higher concentrations of the setting agent resulted in shorter setting times, as ammonia formation and boehmite precipitation during hydrolysis is increased. Increasing green density with increasing shrinkage at the same time was observed for suspensions with constant solids loading but increasing amount of aluminium hydroxide due to the gap-filling characteristic of the hydrophilic nano-powder. The mechanical properties of dried samples correlated well with the evolution of the relative green density as a function of the amount boehmite. An increase of the amount of boehmite resulted in a significant increase in green density and green strength.

In this study it could be demonstrated that with NPAC improved microstructures of green parts can be obtained fabricated with alumina-aluminium hydroxide suspensions. NPAC enables aqueous colloidal suspensions with homogeneous core-shell arrangement of submicron alumina surrounded by nanometer-scaled aluminium hydroxide, which can be transmitted to the green state successfully yielding to an enhanced microstructure. Besides the successful application to the fabrication of all-oxide continuous fiber-reinforced ceramic matrix composites, direct casting of ceramics via NPAC may also attract attention in the field of functional and structural ceramics for the manufacturing of components with tailored microstructures. Combinations of different materials with various functional or structural properties could be enabled to achieve customized material properties.

\section{Acknowledgements}

The authors wish to thank Prof. Walter Krenkel (University of Bayreuth, Germany) for providing the opportunity to use the infrastructure of the department of Ceramic Materials Engineering. The authors also want to thank Marc Schrinner (Physical Chemistry I, University of Bayreuth) for his support in cryo transmission electron microscopy, Werner Reichstein and Bernd Martin (both Ceramic Materials Engineering, University of Bayreuth) for their support in scanning electron microscopy and technical issues. 


\section{References}

1. Lange FF. Powder Processing Science and Technology for Increased Reliability. Journal of the American Ceramic Society. 1989; 72:3-15. http://dx.doi.org/10.1111/j.1151-2916.1989. tb05945.x

2. Reed JS. Principles of Ceramic Processing. New York: Wiley; 1995.

3. Lewis JA. Colloidal Processing of Ceramics. Journal of the American Ceramic Society. 2000; 83:2341-2359. http://dx.doi. org/10.1111/j.1151-2916.2000.tb01560.x

4. Sigmund WM, Bell NS and Bergström L. Novel PowderProcessing Methods for Advanced Ceramics. Journal of the American Ceramic Society. 2000; 83:1557-1574. http://dx.doi org/10.1111/j.1151-2916.2000.tb01432.x

5. River RD. Method for Injection Molding Powder Metal Parts. US patent 4113480. 1976.

6. Novich BE, Sundback CA and Adams RW. Quickset Injection Molding of High-Performance Ceramics. Ceramic Transactions. 1992; 26:157-164.

7. Janney MA, Omatete OO, Walls CA, Nunn SD, Ogle RJ and Westmoreland G. Development of Low-Toxicity Gelcasting Systems. Journal of the American Ceramic Society. 1998; 81:581-591. http://dx.doi.org/10.1111/j.1151-2916.1998. tb02377.x

8. Wang $\mathrm{L}$ and Aldinger F. Temperature Induced Forming. Ceramic Forum International. 1999; 77:E25-E26.

9. Gauckler LJ, Graule T and Baader F. Ceramics forming using enzyme catalyzed reactions. Materials Chemistry and Physics. 1999; 61:78-102. http://dx.doi.org/10.1016/S02540584(99)00117-0

10. Balzer B, Hruschka MKM and Gauckler LJ. Coagulation Kinetics and Mechanical Behavior of Wet Alumina Green Bodies Produced via DCC. Journal of Colloid and Interface Science. 1999; 216:379-386. PMid:10421745. http://dx.doi. org/10.1006/jcis.1999.6293

11. Graule TJ, Gauckler LJ and Baader FH. Direct coagulation casting, a new green shaping technique, Part I: Processing Principles. Industrial Ceramic. 1996; 16:31-34.

12. Novak $\mathrm{S}$ and Kosmac T. Principles of the Hydrolysis Assisted Solidification (HAS). Process for Forming Ceramic Bodies from Aqueous Suspension. Journal of the European Ceramic Society. 2002; 22:289-295. http://dx.doi.org/10.1016/S09552219(01)00287-4

13. Novak S, Kosmac T, Krnel K and Drazic G. Preparation of Alumina Ceramics from Aqueous Suspensions Employing the Hydrolysis of Aluminium Nitride. Journal of Materials Research. 2002;17:445-450. http://dx.doi.org/10.1557/ JMR.2002.0062

14. Kosmac T, Novak S and Sajko M. Hydrolysis-Assisted Solidification (HAS): A New Setting Concept for Ceramic Net-Shaping. Journal of the European Ceramic Society. 1997; 17:427-432. http://dx.doi.org/10.1016/S0955-2219(96)00175-6
15. Simon RA. Development and Colloidal Processing of Novel Oxide/Oxide Composites.[Tese]. Leoben: University of Leoben; 2004.

16. Simon RA. Progress in Processing and Performance of PorousMatrix Oxide/Oxide Composites. International Journal of Applied Ceramic Technology. 2005; 2:141-149. http://dx.doi. org/10.1111/j.1744-7402.2005.02016.x

17. Simon RA and Danzer R. Verfahren zur Herstellung eines insbesondere porösen keramischen Formkörpers und damit hergestellten Formkörper. AT patent. 504168B1. 2008.

18. Simon RA and Danzer R. Process for Producing an in particular Porous Shaped Ceramic Body and Shaped Body Produced Thereby. US patent. 20090325442. 2009.

19. Loebbecke B, Knitter R and Haußelt J. Rheological properties of alumina feedstocks for the low-pressure injection moulding process. Journal of the European Ceramic Society. 2009; 29:1595-1602. http://dx.doi.org/10.1016/j jeurceramsoc.2008.11.001

20. Derjaguin V and Landau LD. Theory of Stability of Highly Charged Lyophobi Sols and Adhesion of Highly Charged Particles in Solutions of Electrolytes. Acta Physicochimica U.R.S.S. 1941; 14:633-652.

21. Verwey EJW and Overbeek JTG. Theory of Stability of Lyophobic Colloids. Amsterdam: Elsevier; 1948.

22. Rahaman MN. Ceramic Processing. Boca Raton: Taylor \& Francis; 2007.

23. Reiner M. Rheologie in elementarer Darstellung. München: Carl Hanser; 1969.

24. Mezger TG. Das Rheologie Handbuch. Hannover: Vincentz Network; 2006

25. Ananthakumar S and Warrier KGK. Extrusion Characteristics of Alumina - Aluminium Titanate Composite Using Boehmite as a Reactive Binder. Journal of the European Ceramic Society. 2001; 21:71-78. http://dx.doi.org/10.1016/S09552219(00)00164-3

26. Pierre AC and Uhlmann DR. Gelation of Aluminium Hydroxide Sols. Journal of the American Ceramic Society. 1987; 70:28-32. http://dx.doi.org/10.1111/j.1151-2916.1987.tb04848.x

27. Wyss HM, Tervoort EV and Gauckler LJ. Mechanics and Microstructures of Concentrated Particle Gels. Journal of the American Ceramic Society. 2005; 88:2337-2348. http://dx.doi. org/10.1111/j.1551-2916.2005.00622.x

28. Emig G and Klemm E. Technische Chemie. Berlin: Springer; 2005.

29. Baader FH. Enzymkatalysiertes Formgebungsverfahren für Aluminiumoxid-Keramiken. [Tese]. Zurih: ETH Zurih; 1995.

30. Kwon S and Messing GL. Constrained densification in boehmite-alumina mixtures for the fabrication of porous alumina ceramics. Journal of Materials Science. 1998 33:913-921. http://dx.doi.org/10.1023/A:1004347425011 